\title{
Hamsa
}

Journal of Judaic and Islamic Studies

$5 \mid 2019$

Muslims and Jews in Latin America

\section{La generación de 1927: la segunda gran oleada de migración palestina a Guatemala}

\section{Néstor Véliz Catalán}

\section{(2) OpenEdition}

1 Journals

\section{Edición electrónica}

URL: https://journals.openedition.org/hamsa/405

DOI: 10.4000/hamsa.405

ISSN: 2183-2633

\section{Editor}

CIDEHUS - Centro Interdisciplinar de História Culturas e Sociedades da Universidade de Évora

\section{Referencia electrónica}

Néstor Véliz Catalán, «La generación de 1927: la segunda gran oleada de migración palestina a Guatemala», Hamsa [En línea], 5 | 2019, Publicado el 31 marzo 2019, consultado el 15 septiembre 2021. URL: http://journals.openedition.org/hamsa/405 ; DOI: https://doi.org/10.4000/hamsa.405

Este documento fue generado automáticamente el 15 septiembre 2021

\section{(c) (i) (9)}

Hamsa est mise à disposition selon les termes de la Licence Creative Commons Attribution - Pas d'Utilisation Commerciale - Pas de Modification 4.0 International. 


\title{
La generación de 1927: la segunda gran oleada de migración palestina a Guatemala
}

\author{
Néstor Véliz Catalán
}

\section{Introducción}

1 Esta investigación presenta, como parte inicial, un análisis de las políticas migratorias de las dictaduras liberales en Guatemala y la región centroamericana. Esto se debe a que los gobiernos promovieron, durante el llamado "Régimen Liberal" una política de fronteras abiertas para todos aquellos migrantes dispuestos a desarrollar la economía y la productividad.

2 A continuación, se realiza una contextualización histórica de las migraciones palestinas, estableciendo como precedentes a los desplazamientos hacia América las problemáticas acumuladas por el Imperio Turco Otomano, que administró Palestina hasta fines de la Primera Guerra Mundial, así como el inicio del éxodo judío a Tierra Santa, lo que conllevó la adquisición de tierras por migrantes procedentes de Europa, donde eran reprimidos por muchos gobiernos.

3 Seguidamente, se inicia a ubicar a los palestinos como un sector emergente a partir de su vinculación al comercio, una actividad menospreciada por las élites criollas y que se tornó lucrativa debido a la escasa industrialización de Centroamérica. Esto implica contactar con una de las familias más exitosas de migrantes, la Abularach, integrada al presente a los grupos dominantes de la economía, finanzas e industria.

Luego se presenta el arribo de palestinos a Guatemala a través de Puerto Barrios a fines de 1927 como una de las oleadas que constituye, ubicándola como parte de los desplazamientos de población árabe desarrollados antes de 1948, fecha que constituye un parteaguas en la Historia de Palestina. Asimismo, se presenta el contexto de problemas y disputas en torno a las condiciones para el ejercicio de la actividad comercial que hubieron de enfrentar los grupos de palestinos residentes y los recién 
llegados, con el agravante de la existencia de "alertas" en grupos de comerciantes ante el riesgo de que los mismos constituyeran una competencia desleal.

5 También se aborda el corte que supone la adopción por parte del gobierno de Jorge Ubico Castañeda (presidente entre 1931 y 1944) de una política racista y excluyente, cuando se adopta la Ley de Extranjería en 1936. Seguidamente, y como síntesis que reúne los resultados de esta investigación, se elaborar conclusiones al respecto de las temáticas y problemáticas abordadas.

\section{Condiciones políticas que permitieron la migración palestina a Guatemala y Centroamérica'}

\subsection{Las políticas migratorias de los gobiernos liberales 1871-1949²}

6 Para emprender el estudio de la presencia árabe y palestina en Centroamérica, hay que recalar en varios elementos de peso en la Historia y la formación del Estado y las sociedades centroamericanas. Por ello, es imprescindible mencionar, como elemento fundamental en la acogida a estas migraciones, las políticas emprendidas por los regímenes liberales en el último tercio del siglo XIX, las cuales se elaboraron para atraer el asentamiento de ciudadanos extranjeros que se emplearan en la agricultura, comercio o la industria y estimularan el desarrollo económico.

El incentivo a la migración de extranjeros responde a que pensaban que, introduciéndolos como colonizadores, lograrían el despegue de las actividades productivas que a su vez elevaran el nivel de vida y cultura del campesinado. La ausencia de inversión pública por parte del Estado se explicaba por la bancarrota financiera, resultado del endeudamiento y la incapacidad estructural de generar recursos de los cuales conformar un presupuesto nacional.

8 Anteriormente, el "primer liberalismo" había propiciado la apertura de fronteras a migrantes europeos como parte de las políticas de libre concurrencia e incentivo a las actividades productivas. La experiencia política que supuso la existencia de la Federación Centroamericana, al finalizar en 1839, aplazó las reformas hasta 1871, fecha del triunfo definitivo de la Revolución liberal, que de Guatemala se expandió a países vecinos como El Salvador y Honduras.

9 Las mismas fueron la continuación de esfuerzos emprendidos durante el primer período de gobierno liberal liderado por Francisco Morazán en la región y Mariano Gálvez en Guatemala entre los años 1831-1838. Estos gobiernos suponían que la afluencia de migrantes europeos traería consigo el progreso y la civilización en un país casi enteramente rural y con una gran mayoría de población campesina e indígena.

Para los gobiernos liberales del siglo XIX, era imprescindible "plantar las raíces" del desarrollo para superar el atraso propio del período colonial. Por lo mismo promovieron reformas económicas y políticas que afectaron a las órdenes religiosas y a las comunidades indígenas, puesto que priorizaron el establecer el mercado de tierras quitándolas de "manos muertas".

11 Sobre todo en Guatemala, el gobierno de Justo Rufino Barrios (1873-1885), "El Reformador", los nuevos cultivos fueron impulsados por una cartera específica, el Ministerio de Fomento. A través de leyes al efecto, promovió la inmigración de extranjeros y su asentamiento en territorios donde pudieran aplicar sus conocimientos 
y experiencia en la agricultura incentiva, lo que llevó al asentamiento de alemanes en el departamento de Alta Verapaz.

\subsection{La crisis del Imperio Turco-Otomano}

12 Los árabes en general y palestinos en particular, inician su arribo en condiciones especiales desde 1880. Ciertas políticas llevadas a cabo por la administración turca facilitaron el inicio de la diáspora palestina. Hasta fines del siglo XIX, también se registró el arribo de judíos al territorio ocupado por ellos, como resultado de las políticas aplicadas después del Congreso Sionista de 1897 convocado por Teodor Herzl en Basilea, Suiza.

En algún momento se aprecia un paralelo entre la migración palestina y la libanesa, debido a la rápida relación que los periodistas y funcionarios gubernamentales hicieron entre ambos guiados por la cultura y el idioma, así como el provenir ambos del Imperio Turco. Sin embargo, la presencia libanesa se puede rastrear un poco más atrás de la palestina y la siria, debido a la incorporación del Monte Líbano a la órbita francesa después de la intervención que 1860. Según el Emperador Napoleón III, este movimiento tuvo entre sus principales argumentos la sospecha de que ahí, turcos, árabes y drusos masacraban inmisericordemente a los cristianos, ante lo que Occidente debía involucrarse. Modernamente, Pascal Herren opina que la expansión imperialista en el Mediterráneo oriental era el principal móvil de este gobernante para darle a la intervención una justificación humanitaria ${ }^{3}$.

En los países del istmo, Panamá y las cinco repúblicas que alguna vez formaron la Federación Centroamericana ${ }^{4}$, también se hizo sentir la presencia de los árabes palestinos $^{5}$ La denominación de estos migrantes supuso un problema para los funcionarios, quienes les registraban como "turcos", eso debido a la documentación con que se presentaban en aduanas y puestos de control, la mayor parte de ellos en instalaciones portuarias ${ }^{6}$. Este calificativo los acompañó en el habla y el imaginario popular en sus primeras décadas de coexistencia con la sociedad urbana mestiza y criolla de los países a que arribaban, omitiendo inconscientemente su origen árabe.

Sin embargo, la migración palestina a tierras centroamericanas se incrementó después de la derrota del Imperio Turco Otomano en la Primera Guerra Mundial, hecho que dio paso a una intensificación de la migración judía a Tierra Santa, así como a la legislación británica, que prohibía a los árabes de dicho territorio registrarse como terratenientes. Esto constituye una condición fundamental para la intensificación de la presencia palestina en Hispanoamérica, que se da en oleadas migratorias estudiadas al presente en estudios con un fuerte componente prosopográfico ${ }^{7}$.

\subsection{La presión de la migración hebrea desde Europa y la ocupación judía de Palestina antes de la Primera Guerra Mundial}

16 El contexto más inmediato para explicar la diáspora palestina y su proyección a Centroamérica es la gradual ocupación de migrantes judíos que arribaron a tierras ocupadas por los árabes sosteniendo el derecho histórico de ocupar la tierra de Canaán pese a la misma tener presencia de otros pueblos, argumento invocado por los activistas y agentes sionistas. La diáspora hebrea inició, como se sabe, a través de la 
acción de los romanos, que en tiempos de Tito destruyeron el Segundo Templo y esparcieron a los judíos por todo el Imperio.

Si bien las autoridades turcas no fueron totalmente permisivas con el sionismo, cuando se produjo la derrota del Imperio Otomano, la declaración Balfour del 2 de noviembre de 1919 dio lugar a una oleada de migrantes que, desde Europa arribaron para hacer realidad la ansiada obtención de una patria judía. Por lo mismo, los hebreos procedieron a la ocupación de territorio con vocación agrícola de una forma singular, colonizando a través de los kibutz, en los que los ocupantes, los kibutzin, trabajaban en un régimen colectivista y estaban organizados militarmente.

Esto produjo abundantes roces entre los recién llegados y los árabes, dando lugar a serios incidentes en los que la Historia muestra algunas masacres, cometidas de ambos lados. Por los palestinos, es tristemente célebre la de Deir Yassin de abril de $1948^{8}$, en la que decenas de hombres, mujeres y niños árabes desarmados fueron muertos por fuerzas paramilitares hebreas, tal como ocurrió en muchas poblaciones árabes; mientras tanto, por el lado hebreo es también digna de mencionar la de Hebrón, realizada en 1929.

19 Asimismo, en el desarrollo de la Segunda Guerra Mundial, el arribo de más inmigrantes judíos que huían de la persecución fascista supuso el inicio de la ocupación formal del territorio. En ese tiempo, el arribo a las costas mediterráneas del barco "Éxodo" con tripulantes judíos que huían de Europa, dio lugar al apoyo internacional a la causa de los sionistas. Pronto, la autoridad británica se tornó abiertamente incapaz de controlar los desmanes de los grupos armados, que empezaban los roces a una escala cada vez más pronunciada.

20 Algunos grupos judíos desarrollaron alas paramilitares que ejercieron la actividad armada a través del terror. Entre ellos, por mencionar algunos, se encontraban la Haganá, el Palmach Irgun, y el Stern Group. A la vez se conformaban brigadas palestinas como las constituidas por el clérigo Ezzedine al Qassam, fundador de la "Mano Negra", mítico combatiente cuyo nombre ha sido reivindicado recientemente por uno de los brazos armados de la OLP. Todo este panorama de crispación y enfrentamiento se intensificó cuando las Naciones Unidas decidieron legitimar la aspiración hebrea de conformar un Estado el 9 de mayo de 1948.

\section{El comercio, la rama preferida de inserción de los árabes palestinos en Centroamérica}

\subsection{Condiciones y contexto en el que los palestinos se insertan a la actividad comercial}

En la mayor parte de países de arribo, los árabes palestinos se insertaron pronto en actividades económicas de tipo comercial, asumiendo el rol de intermediarios. Es frecuente encontrarlos en narraciones y referencias dispersas como vendedores ambulantes y propietarios de almacenes, tiendas y bodegas, configurándose una circunstancia particular para la reproducción de capital comercial. Para René Poitevin Dardón, autor de la obra "La industrialización en Guatemala", los árabes son un grupo emergente que surge como intermediario entre la masa de consumidores y los 
productores ganando espacio a partir de la compra al por mayor y la reventa al menudeo'.

Ello lo explica la limitada actividad mercantil en una sociedad regida por fracciones oligárquicas terratenientes, que sostenían una noción tradicionalista de la riqueza, entendiéndola como patrimonio heredado por la sangre y los vínculos familiares. En el imaginario de las élites terratenientes, herederas de las prerrogativas de los criollos coloniales, el dinero no es un medio de riqueza por excelencia, sino la tierra. El feudalismo ibérico, trasladado a América con la conquista y colonización, priorizó las actividades agrarias sobre cualquier renglón, lo que condicionó la existencia del latifundismo como modo y forma dominante de reproducción de las relaciones sociales.

Esta había sido la tónica que marcó la existencia y conformación de las redes familiares criollas que obtuvieron la validación de su poder económico al acceder el país a la independencia en 1821. Luego, las mutaciones en el signo ideológico dominante, los "cambios de régimen", fueron reacomodos de las élites que ocurrieron tras el desarrollo de coyunturas conflictivas apreciadas como conflictos y guerras entre liberales y conservadores.

Las formas de acumulación fueron preferentemente agrarias, existiendo una dependencia de cultivos como el añil, la grana y el café, los que fueron puntales económicos de Guatemala desde la independencia hasta después de la finalización del régimen liberal tras la Revolución de octubre de 1944. Debido a esas características, especialistas como Julio Castellanos Cambranes, Julio César Pinto Soria y Sergio Tischler Visquerra no dudan en calificar el capitalismo guatemalteco como agrario ${ }^{10}$, puesto que no superó las condicionantes que planteaba la dependencia de la producción agrícola como medio de acumulación y, que a pesar de la industrialización incipiente en zonas urbanas, el mayor rubro de exportación ha sido el de productos agrícolas ${ }^{11}$.

Debido al carácter dependiente de la región centroamericana, otras formas de producción, trabajo y obtención de plusvalía fueron aplazadas, desarrollándose tardíamente la industria manufacturera y retrasándose en grado sumo el ramo primario, la industria pesada. Si existió una conexión con el movimiento capitalista exterior, la misma se dio a partir de concesiones de los gobiernos liberales a grandes emporios y monopolios, como lo fue la United Fruit Company, beneficiaria directa de la política del presidente Manuel Estrada Cabrera a partir de 1903.

Por otro lado, desde 1920 en adelante, tienen lugar los primeros atisbos de industrialización y la diversificación del consumo con la apertura del comercio y la producción desplegada por algunas fábricas, entre las que destacaron las cervecerías, ingenios azucareros y cementeras, éstas últimas dirigidas por la familia Novella, de ascendencia italiana. El arribo de los palestinos y chinos y su dedicación al comercio informal permitió el flujo de mercancías aún no producidas en una magnitud masiva debido al escaso desarrollo industrial, tales como telas, botones, agujas, etc. las que también eran trasegadas por comerciantes chinos, expandidos estos por casi todo el país.

En la región, la industrialización se encontraba en estado incipiente y era impulsada con las reservas del caso, pues formaba una rama con una ganancia incierta y que dependía de la apertura y existencia del mercado interno. Sin población con poder adquisitivo, apostar por la introducción de mercancías que no podían realizarse era un reto para la mentalidad oligárquica y señorial predominante en los grupos criollos. 


\subsection{Los palestinos en Guatemala, otro episodio de una diáspora exitosa en el istmo centroamericano}

Recientemente, algunos especialistas e interesados en el tema de la diáspora palestina se han dado a conocer a través de internet algunos trabajos sobre las comunidades palestinas de países vecinos como Honduras y El Salvador ${ }^{12}$, donde la minoría palestina desempeña un destacado papel en la economía y la política en la actualidad ${ }^{13}$. Analizando algunos de ellos se encuentra un común denominador: la contribución de los investigadores al estudio y conocimiento de las formas de inserción de dichos migrantes en la vida social, económica y política de los países a que arribaron ${ }^{14}$.

En el momento actual, para Guatemala, puede decirse que existen pocas referencias a los árabes palestinos, a su presencia e inserción en la sociedad a partir de la migración. En Guatemala, al momento (2018) existen escasas referencias bibliográficas y documentales que esclarezcan la evolución de la migración palestina en particular y árabe en general. En ello han influido las prácticas investigativas de muchos profesionales de la Historia y las Ciencias Sociales y tendencias de las instituciones que financian procesos de investigación. En líneas generales, no existe una política de incentivo o apoyo a estos procesos debido a condicionamientos extra-académicos y el peso de ciertas demandas sectoriales ${ }^{15}$.

Se carece, a la fecha, de estudios propiamente dedicados a ello, lo que ha sido una constante en países vecinos antes del desarrollo de la Historia Ciencia y del inicio de los estudios sobre movilidad humana, diásporas y migraciones intercontinentales, promovidos por centros de investigación o fundaciones privadas que se han encargado de realizar trabajos más o menos focales, en los que las minorías son objeto de amplio estudio que conlleva fases de gabinete y de campo.

31 Al respecto, el realizador de este trabajo en el que se reseñan dos oleadas migratorias en las que los palestinos arribaron al país en el siglo XX una localizada en 1927, que es la continuación del éxodo iniciado en el siglo anterior y otra, más reciente, iniciada en 1967, fecha de la derrota de los ejércitos árabes ante Israel e inicio de la oposición armada al Estado Hebreo de parte de diversas facciones, entre las cuales, la mayormente reconocida fue la OLP de Yasser Arafat ${ }^{16}$.

Antes de 1927, encontramos una corriente de migrantes palestinos cuyo referente más sobresaliente es la familia Abularach, que arribó al país a fines del siglo XIX. La misma es originaria de la ciudad de Belén e inmigró debido a las políticas de los sultanes otomanos que administraban Palestina y a que, debido al eco que tuvo la convocatoria de Teodor Herzl, ya se experimentaba cierta presión de judíos que arribaban desde Europa huyendo de las persecuciones en su contra ${ }^{17}$.

A decir del Dr. Freddy Abed, autor de un material monográfico consultado por quien escribe estas líneas, la misma sigue desarrollándose en el presente y los nuevos arribos registrados, son una prolongación de la diáspora provocada e intensificada por la ocupación israelí de los territorios palestinos y el consiguiente desarrollo del conflicto $\operatorname{armado}^{18}$. No se trata ya de un movimiento incentivado por los gobiernos de los países de arribo, sino de la continuación de un flujo cuyas causales están presentes en la escasez de tierra y espacio bajo la ocupación de Israel y la ausencia de una entidad palestina independiente. 


\section{que los llevó a América Central. Guatemala fue uno de los países en los que se unieron a migrantes de origen árabe ya asentados como parte de la diáspora libanesa. Posteriormente a esa fecha, existe necesidad de inquirir sobre si, quienes arriban, descienden de los asentados en las oleadas que se abordarán aquí, o bien resultan distintos y autónomos frente a ellos. Es posible que, la presencia de poco más de un siglo haya sido tiempo suficiente para establecer redes familiares y acoger a nuevos migrantes. Los palestinos han trascendido los límites étnico-raciales y, en algunos casos, se han mezclado con mestizos y descendientes de criollos de ascendencia española. \\ 2.3. La familia Abularach, uno de los linajes pioneros en la migración palestina} 1948, los palestinos migraban hacia Europa y América, existiendo una gran corriente

\subsubsection{Una red familiar con presencia a lo largo y ancho de Iberoamérica}

Esta familia es, con mucho, la más importante en la migración palestina hacia Guatemala. Como otras, se constituye de ramas cristianas y procede de Belén, de donde sus integrantes migraron a finales del siglo XIX. Se trasladó a tierras americanas, registrando presencia en varios países a saber: México, Guatemala, El Salvador, Honduras y Bolivia. Tenía su principal reducto en Belén, una ciudad emblemática para el cristianismo, tanto en sus vertientes occidental como oriental.

En Guatemala es quizás donde más impacto ha tenido, trascendieron a través del comercio, actividad que les convirtió en capitalistas y propietarios de establecimientos comerciales, lo que les permitió enlazar con familias dominantes locales. Documentación de archivo revela que, para 1892, Jorge Abularach ya se encontraba en el país y solicita, el día 12 de julio que se le rebaje el monto del precio que se le arrendaba por la Municipalidad por el uso de un inmueble donde instaló su establecimiento comercial ${ }^{19}$. Se trata del primer palestino presentado comerciante, si bien la sospecha de la presencia de un extranjero de origen árabe asoma en una referencia a la autorización que hizo el Ayuntamiento para brindar espectáculos públicos en abril de 1859 al malabarista Santiago (Jacques) Abdala ${ }^{20}$, presentado como de nacionalidad francesa dos años después, en $1861^{21}$.

Para 1889, Antonio Abularach es ya un comerciante que cuenta con un local donde vende mercaderías varias, enseres domésticos, toallas, agujas, encajes y otros materiales de costura. El día 31 de mayo de ese año escribe al Jefe Político del departamento de Guatemala identificándose como "ciudadano turco natural de Palestina"22; esto lo hace pidiendo una autorización para llevar a cabo una rifa de excedentes de las mercancías que expende, lo cual, debido a la política gubernamental de entonces es denegado ${ }^{23}$. 
39 El fin del siglo XIX presenció el arribo del clan a Guatemala, pues algunas referencias documentales sugieren la presencia de Jorge, Antonio y Natalio del mismo apellido. Según el pintor Rodolfo Abularach, sus ancestros Antonio y Natalio Abularach Gabriel llegaron al país en $1893^{24}$. Natalio fundó el Almacén "El Tirador" en el que vendía telas, fósforos, calcetines, baterías para linternas y otros productos, teniendo como insignia un jinete árabe montado sobre un caballo blanco disparando con un fusil ${ }^{25}$. Su hijo, Félix Gabriel (1883-1937) continuó con el desarrollo del comercio, siendo su nieto José Félix Vicente (1922) uno de los más grandes empresarios guatemaltecos al presente, dueño de Aceros de Guatemala y otras empresas. Para el analista Bill Barreto, se trataba de una migración que fue tolerada y permitida por las autoridades, recibiendo tras su éxito en el comercio minorista el desdén de la élite criolla oligárquica ${ }^{26}$.

40 A inicios del siglo XX, el 17 de enero de 1902, a Jorge se le encuentra asociado a otro palestino, Carlos Dacaret, solicitando a las autoridades ediles la autorización para ampliar sus locales comerciales en el céntrico "Portal del Comercio", antiguo "Portal de Aycinena" o "Portal de los turcos", ubicado frente a la Plaza Central y Catedral Metropolitana, donde ocupan los locales 5 y 6, así como para adquirir otro espacio similar $^{27}$.

\subsubsection{Revisando los antecedentes más remotos}

41 Los Abularach descienden de una de las 24 familias en que se dividió el clan cristiano Tarakmé, entre los cuales existen otros de mucha presencia en Centroamérica como Babdoub, Daued, Sabat y Talamás. En documentación expedida por la Parroquia Latina de Santa Catarina de Belén, Palestina, aparecen también referencias a otro clan de cristianos árabes palestinos: el Najajreh, compuesto de 25 familias. Estos documentos son importantes debido a que muestran las fechas de los enlaces matrimoniales entre familias de los clanes y su inserción en algunos países de Iberoamérica, logrando observarse casamientos con residentes locales, personas no árabes ${ }^{28}$.

El miembro de esta familia cuyo nacimiento se registra más atrás en el tiempo es Giubrail Issa Abularach, nacido en Belén el 12 de diciembre de 1694 y casado en Santa Catarina con Bárbara George en julio de $1716^{29}$. En documentos más recientes, que reseñan las fechas de celebración de bodas se encuentra que varios varones nacidos en esa ciudad pasaron a Centroamérica, siendo su destino muchas veces la Ciudad de Guatemala $^{30}$. Entre ellos están: Jacub (1845-1917), Giubrail (n. 1869-m. en Guatemala en 1936), Attallah (n. en 1870- m. en Guatemala en 1937), Mikhail (1877-1939), Bishara (n. en 1894- m. en Guatemala en 1956) y Antonio (Halim) (n. 1907- m. en Guatemala en 1967) ${ }^{31}$. Todos ellos arribaron en tiempos en que fueron clasificados como clasificó "turcos" debido a la pertenencia de Palestina al Imperio Otomano a principios del siglo $\mathrm{XX}$.

43 De todos ellos, nacieron en el país 29 personas, registradas ya como ciudadanos guatemaltecos por nacimiento. Los jerarcas, en número de 6, arribaron a Guatemala en diferentes fechas ya casados con pasaporte otomano a excepción de Halim, quien arribó a San Salvador. Uno de sus descendientes, Salvador, nacido en 1900, casó con Blanca Luisa Méndez, siendo el primer Abularach con esposa no palestina.

La importancia de esta familia merece un capítulo aparte en la Historia de la migración palestina, puesto que, su inserción en los grupos de poder económico e influencia derivada de ello en la sociedad guatemalteca es sumamente vasta al presente ${ }^{32}$. Por lo 
que respecta a la migración de 1927, la familia continuó migrando desde Belén e integrándose a la comunidad residente, como lo venía haciendo casi ininterrumpidamente a pesar de las restricciones. Ejemplo de ello es el arribo de Salomón Abularach a Puerto Cortés, en el Caribe hondureño en el barco "S.S. Clanehe" el 18 de junio de 1921. Fue registrado como comerciante de nacionalidad siria por los funcionarios de la embarcación ${ }^{33}$.

Figura 1. Facsimilar de un archivo eclesiástico que muestra la fecha y lugar de nacimiento de los hijos de Salvador Giries Abularach y Blanca-Luisa Méndez

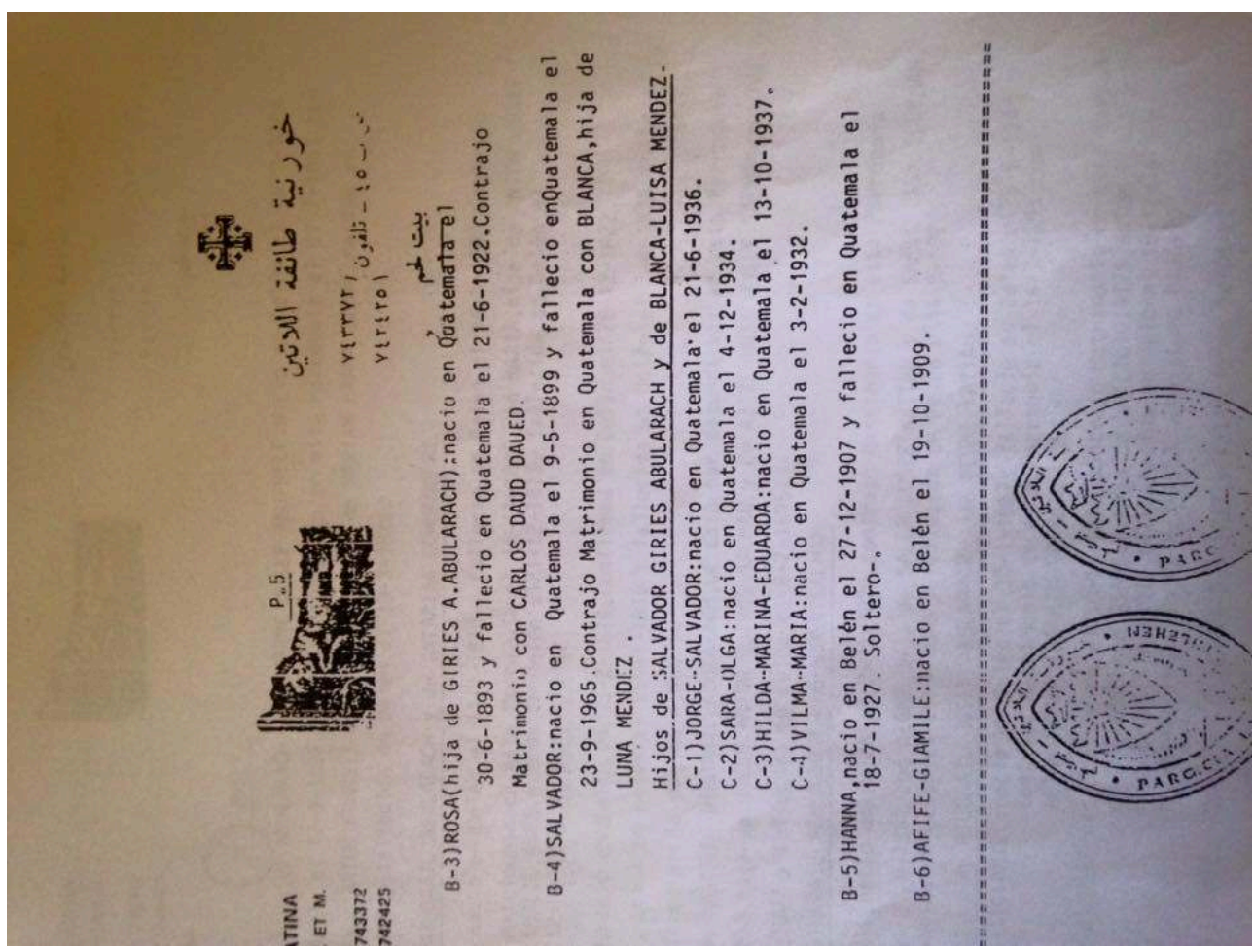

Fuente: página "Genealogía Abularach", disponible en https://www.facebook.com/GenealogiaAbularach-153344181419235/)

\subsection{La segunda migración significativa de palestinos a Guatemala en 1927, noticias del arribo}

\subsubsection{La llegada a Guatemala}

Según la Asociación Árabe Guatemalteca, el segundo movimiento migratorio significativo de palestinos hacia este país se dio a fines de 1927, en pleno gobierno del General Lázaro Chacón, uno de los últimos gobernantes liberales. Su vía de ingreso fue el puerto de Puerto Barrios, ubicado en la bahía de Amatique, actualmente cabecera del departamento de Izabal. El barco en el que los inmigrantes se transportaban era el vapor alemán "Rugía", que efectuaba viajes entre la Guaira, en el Caribe de Venezuela y el citado puerto guatemalteco ${ }^{34}$.

Un aspecto sumamente importante de esta migración es que, según relata Freddy Abed, el barco citado zarpó del puerto mediterráneo de Jaffa o Haifa, dirigiéndose hacia el Caribe en travesía directa hacia la Guaira. En el mismo se encontraba como pasajero el señor Musa Abed, quien, interesado en llegar a Guatemala, emprendió un viaje hacia 
ahí en fecha 15 de noviembre del citado año. Este migrante es antepasado de los hermanos Jorge y Freddy Abed, que colaboraron con el autor a recabar datos y material fotográfico para esta investigación ${ }^{35}$.

\subsubsection{Los componentes de la migración}

Existen referencias de que, algunos migrantes palestinos que arribaron en 1927 habían sostenido estancia en Chile, como es el caso de Jorge Massis y Basma de Massis o en México, como sucedió con Salomón Zaid y su esposa, Elodia de Zaid. (Abed 1999) Entre los pioneros en arribar a Guatemala se encuentran también Tomás Khoury, Hanna Abed, Abu Tayeg y Mijail Musalam ${ }^{36}$. El primero de ellos manifiesta una filiación libanesa, lo que no extraña cuando se abordan las oleadas migratorias de árabes a América, donde se encuentran muchas veces palestinos, libaneses y sirios formando redes $^{37}$.

Figura 2. De pie arriba, derecha a izquierda: Salomón Andaraus, Abdallah Andaraus, Musa Abed, Sabri Diab, sentados, en la misma dirección: Antonio Aranki, Salomón Dary un periodista libanés no identificado y Pedro Muadi. Algunos de ellos llegaron a Guatemala a bordo del buque alemán "Rugía" en noviembre de 1927. Fotografía inserta en el material consultado elaborado por el Dr. Freddy Abed.

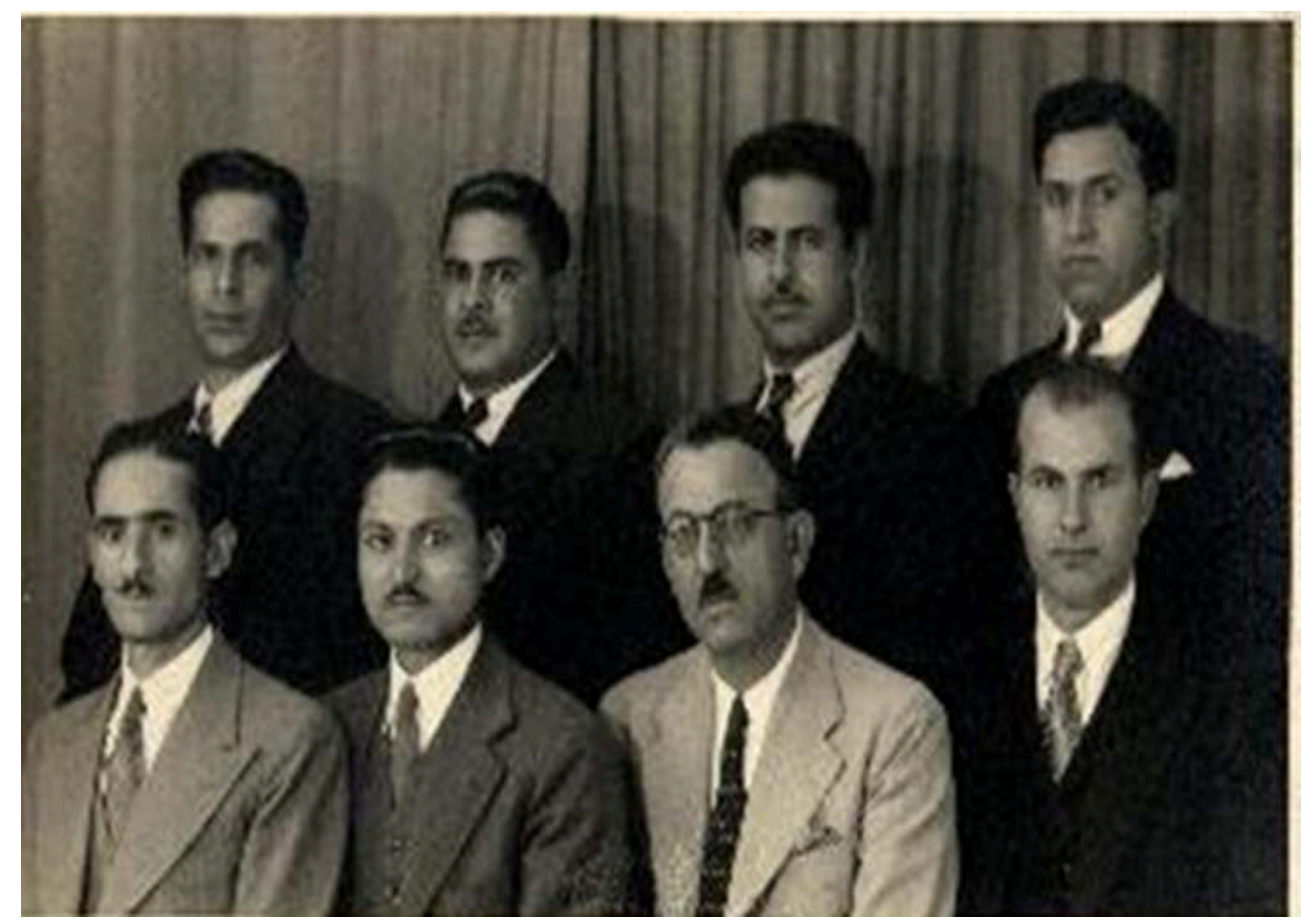

Se menciona que la actividad en la que se insertaron estos migrantes, en un inicio, fue el transporte de ganado vacuno criado y engordado en el sur del país hacia el principal mercado, la ciudad capital, con lo cual se convirtieron en intermediarios obteniendo en un principio pingües ganancias ${ }^{38}$. Por lo mismo, exploraron también los renglones agrícola y ganadero, pero con el tiempo lograron engancharse en la venta de mercancías diversas que compraban a precio de mayoreo en los puertos para luego comercializarlas en las ciudades ${ }^{39}$.

Así, procedieron como sucedió con otros grupos de países vecinos, los que lograron acaparar el comercio minorista de ropa, calzado, enseres domésticos y demás, irrumpiendo como competencia para casas locales dedicadas a comercializar productos 
industriales de fabricación local o externa, las que eran de guatemaltecos o de otros migrantes dedicados al comercio, como lo podían ser españoles, italianos, alemanes, judíos o chinos ${ }^{40}$.

50 La urbanización y la ampliación de los segmentos de consumo con el aumento del poder adquisitivo les permitieron encontrar clientes y compradores, desarrollando capas más amplias de minoristas y surtiendo la demanda doméstica, que crecía aceleradamente mientras sectores de migrantes campesinos se integraban a la urbe capitalina. Este contexto es en el que se puede encontrar el inicio del establecimiento de tiendas y almacenes propiedad de los palestinos, algo que los distingue al presente.

51 Entre quienes arribaron a Guatemala en noviembre de 1927 se encontraban Sabri y Lufti Diab, Giries Gibrán, Hanna Abu Zaid, Musa Abed, José Diab, Majid Massis, Jorge Massis, José Massis, Pedro Muadi, Antonio Aranki, Bajih Yagnam, Shijan Younes y los hermanos Jorge, Salomón y Abdallah Andaraus ${ }^{41}$.

52 Todos ellos, junto a los mencionados al principio contabilizan 24 palestinos. Algunos procrearon hijos con un papel importante en el comercio y la industria en décadas posteriores, no sin antes enfrentar algunos problemas propios de una presencia accidentada, entre la proscripción y la aceptación debido a los prejuicios de la población local y las exigencias de las autoridades. En tiempos finales del gobierno de Manuel Estrada Cabrera (1898-1920), las restricciones se establecieron a los ciudadanos alemanes y de las potencias centrales aliadas como parte de la política que sintonizó la diplomacia local con la de Estados Unidos, última potencia incorporada a la guerra ${ }^{42}$. Para 1927, quienes ingresaron al país ya no cargaban sobre sí esas medidas, si bien había que establecer la existencia de normativas para el ingreso de adultos provenientes de áreas cuya soberanía era tutelada por Gran Bretaña, como sucedía con el Protectorado de Palestina.

\subsubsection{Problemas para la integración de estos migrantes: temor a la competencia desleal en el comercio y racismo, ¿arabofobia en los comerciantes locales?}

53 A pesar de existir redes familiares palestinas en Guatemala, la integración de los migrantes de 1927 no fue fácil. Existía aún gran recelo y racismo de parte de las élites oligárquicas así como también del grueso de la población debido a prejuicios y temores hacia todo elemento extraño a la noción imaginada de país que se tenía entonces. Cuando el grupo de migrantes palestinos que arribaron a Puerto Barrios en el buque alemán "Rugía" tocaron suelo guatemalteco, tenía lugar una situación particular en el contexto de luchas sectoriales por el espacio para ejercer la actividad comercial. Según se puede comprobar en la lectura del diario "El Imparcial", el de mayor alcance en aquella época, algunos sectores comerciales hicieron causa común en contra de los recién llegados basados en la defensa de sus intereses.

54 A pocos días de su llegada un grupo de comerciantes de Quetzaltenango, Totonicapán, San Francisco el Alto y Olintepeque, todas poblaciones del Occidente del país en contra de lo que consideran, ante el presidente Lázaro Chacón, el ejercicio de una competencia desleal de parte de los árabes:

“(..) cansados al mismo tiempo que decepcionados venimos por conducto de estas líneas a hacer patente y pública nuestra protesta enérgica contra los malos empleados de puertos y puntos fronterizos de la república porque no obstante el decreto que restringe la inmigración de ciudadanos de nacionalidad siria, turca, libana (sic), árabe, etcétera, estos individuos dudosos se multiplican como el 
chapulín [langosta] (...) El incumplimiento de la ley nos hace creer que la misma ha venido a constituirse en un medio de explotación para los empleados de marras, quienes a fuerza de componendas se llenan los bolsillos sin acatar el inmenso daño que ocasionan a los hijos del país ${ }^{43}$."

Es llamativo el tono en que un redactor anónimo, a nombre de cerca de doscientos comerciantes, describe y expresa tres problemas para sus patrocinadores:

a. La permisividad de las autoridades con respecto a los migrantes del Medio Oriente, algo que viola la legislación vigente para entonces,

b. El hecho de que los mismos, debido a la corrupción de los empleados estatales, siguen arribando al país aprovechando la escasa vigilancia de puertos y puestos fronterizos y

c. El perjuicio económico que esta inserción hace a los comerciantes locales generando una competencia desleal en el presente $\mathrm{y}$, de continuar las condiciones que la permiten en tiempo futuro.

Todo ello puede resumirse en que, los árabes eran tenidos como indeseables para el grupo de comerciantes locales, que al dedicarse a la comercialización de textiles, como es el caso de los de la región occidental, ven con malos ojos a la competencia.

El acento amargo del redactor al vehiculizar la posición de sus patrocinadores deriva también en una posición racista que, sin embargo, no debe extrañar al ser la exclusión y estigmatización de quienes no "cabían" en el molde de lo aceptado debido a las dinámicas propias de la sociedad guatemalteca:

“(...) al presidente se le ha hecho saber de los graves males que acarrean al país los comerciantes de las razas mencionadas (...) ${ }^{44 "}$

Otro factor que incidió en la crispación que se puede notar en este documento es el aumento de las tarifas para legalizar la licencia de comercio, algo que, podría decirse que "preparó el camino" para la estigmatización de los palestinos. La cuota exigida se elevó a diez quetzales sin justificación alguna ${ }^{45}$, así como se estableció como obligatoria la presentación de un razonamiento o actualización de la licencia legalizada por un abogado y notario ${ }^{46}$.

59 Todo esto hizo que los árabes fueran adversados de una forma intensa, manifestando una visión pesimista de la convivencia de ambos grupos de cara al futuro:

“(..) seguramente llegará el día en que dado el control competencia y propaganda de los comerciantes turcos, sirios etc. el hambre acose a nuestros hijos que morirán sin amparo (...)" 47

60 Asimismo, hay un factor a resaltar en este interesante documento con respecto a la naturaleza del registro y control de la inmigración palestina, cuestionada con anterioridad por los comerciantes locales. Existe la certeza, en este grupo de que los palestinos y demás extranjeros de origen árabe se han introducido a Guatemala de forma ilegal, amparados en la corrupción de las autoridades y empleados subalternos que, a cambio de soborno, "han hecho de la vista gorda" ante la llegada de los migrantes, sugiriendo la práctica de sobornos. En tono de denuncia, así lo manifiesta el redactor del "Memorándum":

“(...) Repetimos nuestra protesta contra los extranjeros aventureros de que nos ocupamos cuando los empleados que defraudan (sic) las esperanzas de la patria permitiendo la inmigración clandestina $(. . .)^{48 "}$

61 Este último argumento explica la ausencia de registros confiables de palestinos migrantes en documentos de inscripción de ciudadanos extranjeros, registro de visitantes y demás expedidos por autoridades como el Ministerio de Gobernación y el 
de Relaciones Exteriores. En Guatemala, la llegada del buque "Rugía" pasó desapercibida en los medios y, es muy probable que, quienes arribaron en él provenientes de Palestina no hayan podido, debido a las barreras idiomáticas y culturales, solventar los requisitos exigidos para legalizar su estancia, a pesar de que, ya no se trataba de súbditos del Imperio Otomano, las desconfianzas hacia ellos eran mayúsculas.

Podría decirse que, la acogida de estos migrantes trajo mayor crispación entre los grupos locales y los nuevos comerciantes. Este malestar que se reflejó El "Memorándum" manifestó el sentir de cerca de doscientos comerciantes, pero no fue la única expresión de este tipo que llegó al presidente de entonces, Gral. Lázaro Chacón. A fines del año 1927, "El Imparcial" publicó también otro documento que, sin hacer referencia directa a los árabes como el documento en que se insertan los argumentos analizados con anterioridad, también deja entrever una preocupación por el contrabando que merma los tabacos nacionales:

(...) Algunos extranjeros y del país intentan introducir tabaco mexicano en detrimento del de Zacapa y Chiquimula (.....49

De nuevo, un redactor anónimo expresa, con sus capacidades, el sentimiento de un conjunto de comerciantes, esta vez vinculados al tabaco, cultivo y rama de la producción históricamente afincada en el Oriente del país. Asimismo, más de un centenar de afectados por el contrabando hacen llegar al gobernante la denuncia referida, mostrando nuevamente, una actitud beligerante contra la competencia sea de "extranjeros" o "del país" 50.

Como vemos, asoman posibilidades para establecer redes familiares al encontrar varios apellidos repetidos, lo que evidencia círculos filiales de comercio, finanzas y negocios. Esto es posible explicarlo debido a la necesidad de la lealtad filial y el guardar los vínculos familiares como garantía de la perpetuación de las propiedades y recursos monetarios adquiridos y legados. Los palestinos, en un inicio se apartaron de cualquier tentativa de mestizaje con la población nativa, selectivizando la acogida de sujetos exógenos, restringiendo el contacto con élites locales, derivando entonces en prácticas de endogamia. En el caso de Guatemala, posteriormente se cruzan con familias mestizas y criollas.

Figura 3. David Bassir, Musa Abed, (llegó a Guatemala en 1927), Ernesto Talgi y José Massis. Fotografía inserta en el material consultado elaborado por el Dr. Freddy Abed.

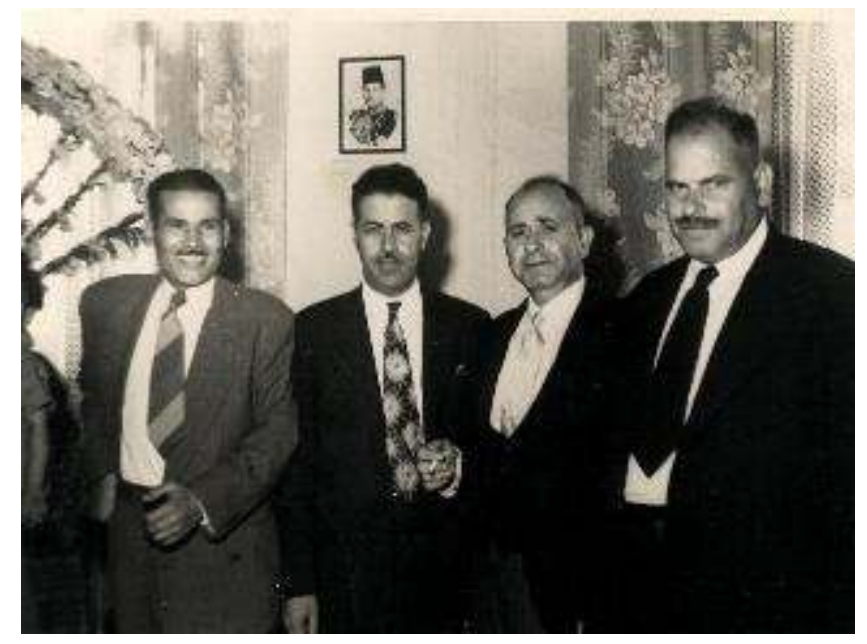



Betlehem, una localidad de amplia resonancia histórica en el mundo occidental por ser el lugar de nacimiento de Jesucristo. Tal fue el caso de los Saca, Jop, Zimeri, Abularach (que ya tenía presencia en el país) y Dacaret, apellidos vinculados desde la primera mitad del siglo XX a la actividad comercial en ciudad de Guatemala ${ }^{55}$. Se trataba, como se ha dicho, de familias que, a pesar de ser étnicamente árabes, profesaban el credo cristiano y lo mantuvieron una vez instalados ${ }^{56}$. Algunos provenían de Taybeh, una localidad cisjordana mayormente cristiana con una floreciente empresa cervecera en la actualidad ${ }^{57}$.

Este aspecto ideológico es de suma importancia al revisar la acogida que se dio a los migrantes en la sociedad. Las autoridades de entonces, celosas guardianas del orden público, no tuvieron en los palestinos a un grupo al que someter a la vigilancia acostumbrada para la población local. El período de arribo de esta primera migración era de redoblamiento de la represión y de vigencia para formas de control sobre los movimientos sindicales y agrupaciones estudiantiles, siempre vistas con el riesgo de ser infiltradas por el comunismo ${ }^{58}$. 


\section{Las prohibiciones de la "era de Ubico"}

\subsection{La ley de extranjería de 1936}

70 No obstante que ya existía una comunidad árabe residente, el gobierno de Jorge Ubico Castañeda, un simpatizante de los regímenes fascistas europeos y seguidor de las políticas eugenésicas como sus predecesores, emitió Ley de Extranjería, en donde se prohíbe la entrada y estadía "De los individuos, cualquiera que sea su nacionalidad, de raza turca, siria, libanesa, árabe, griega, palestina, armenia, egipcia, afgana, indú [hindú], búlgara, rusa ${ }^{59 "}$. Como puede verse, no era lo mismo ser extranjero y occidental, que europeo occidental o blanco asiático ${ }^{60}$.

71 Después de terminado el ubiquismo y de iniciarse la llamada "primavera democrática" con los gobiernos de Juan José Arévalo Bermejo y Jacobo Árbenz desde 1945, se abrió un compás de relajamiento para las medidas represivas estatales y desaparecieron la vigilancia sistemática de la vida pública y las penalizaciones por infringir rígidas leyes existentes. Los palestinos figuraban entonces, pese a la prohibición de 1936, como un elemento en vías de asimilación, de lo que da noticia un texto de la época, al hablar de las migraciones y el transporte aéreo en 1945:

"Las naciones que más movimiento tienen son: Guatemala, EE. UU., México y el Salvador. En todos los países de C.A., hay mucho elemento americano o yankee, inglés, chino, alemán (sobretodo antes de 1939), palestino y suizo ${ }^{61 "}$.

Como puede apreciarse, los palestinos figuran como un importante grupo migrante a la par de varios de ascendencia europea, cuyo asentamiento y arraigo había sido incentivado desde el gobierno por los liberales. La presencia estadounidense es más que lógica, debido a la cercanía geográfica y los vínculos de dependencia con el país del norte que, conforme pasaban los años, iba dejando atrás el particular nexo que Guatemala tuvo una vez con Alemania, más que nada, ante la afluencia de agricultores germanos incorporados al bloque cafetalero una vez que aumentaron sus capitales y alcanzaron el éxito en las cosechas del grano.

Entre los alemanes también existía una porción importante de judíos, siempre presentes en la región desde los inicios del período liberal. Los mismos, debido a la política proteccionista del gobierno, pudieron aclimatarse con éxito y constituir una élite que también, como los palestinos, tuvo en el comercio una de sus principales vías de acumulación y ascenso social, solamente que los hebreos, como ciudadanos alemanes, tuvieron abiertas las puertas para convertirse en terratenientes, algo que los palestinos no lograron.

74 Una ligera revisión a los apellidos de los miembros de la comunidad judía cuyos restos descansan en mausoleos de los cementerios más populosos y antiguos de la ciudad capital de Guatemala, el General y "La Verbena" abiertos para sepultura de todos los sectores sociales, nos arroja una abrumadora mayoría de apellidos alemanes y nombres hebreos, sin duda una consecuencia del arribo de una importante corriente askenazi que no tiene comparación comparada con los sefarditas, por cuanto los migrantes de religión judía son mayoritariamente de origen alemán ${ }^{62}$. 


\section{Conclusiones} muchas dificultades, entre ellas estuvo la de coincidir con el aumento de medidas tributarias que gravaban la actividad comercial local y a necesidad de aprovechar condiciones coyunturales como los excedentes de la producción mundial de textiles para apuntalar su posición como nuevos comerciantes. liberales, el gobierno de Jorge Ubico Castañeda, simpatizante de los regímenes totalitarios y tolerante con el racismo de los países fascistas emitió una ley de extranjería que resultó prohibitiva para los palestinos, cuya presencia era igual de nociva que los europeos orientales e hindúes.

La migración palestina, pese a eventualidades y particularidades muy específicas, se siguió desarrollando previamente a la eclosión de violencia que preludió la proclamación del Estado de Israel en 1948. El arribo de 1927 constituye una vinculante entre los primeros palestinos asentados en Guatemala y otras migraciones, las que tuvieron entre sus motivaciones esenciales el avance de los judíos colonizando Palestina, lo que arrebató tierras a sus ocupantes árabes. 


\section{BIBLIOGRAFÍA}

Archival Sources

Archivo General de Centroamérica (AGCCA), box 78.22, exp. 15585, leg. 705; box 78.32, exp. 35829, leg. 1495; box 78.37, exp. 18372, leg. 765; box 78.7, exp. 13675, leg. 653.

Bibliography

ABED, Freddy, La comunidad palestina en Guatemala, Ciudad de Guatemala, Asociación Árabe de Guatemala, 1999.

AMAYA VANEGAS, Jorge Alberto, "El papel de los inmigrantes palestinos en Honduras 1900-1950", Tegucigalpa, [s.n.], 1995.

CORONA PÁEZ, Sergio Antonio, "Los Abularach Talamás", en "Firmas: crónica de Torreón" 28 de junio de 2015, enlace web: http://www.milenio.com/firmas/dr-_sergio_antonio_corona_paez/ Abularach-Talamas_18_543725657.html [último acceso a 30 de marzo de 2018].

El Imparcial (10 de noviembre de 1927).

"En defensa de los tabacos del Oriente", El Imparcial, (17 de Diciembre de 1927), pp. 1-4.

FELIPE Q., Óscar, "Hospital Nazir hará labor social con los más pobres de Guatemala”, Diario Prensa Libre (julio 3 de 2017), disponible en: http://www.prensalibre.com/ciudades/guatemala/ hospital-nasir-hara-labor-social-con-los-mas-pobresde-guatemalam [último acceso a 30 de marzo de 2018].

GIL FLORES, Gemma, "Musulmanes en Guatemala", Revista D [Diario "Prensa Libre"], (5 de junio, 2005), pp. 20-21.

HERREN, Pascal, “Voltairenet.com. 12 de Diciembre de 2012”, http://www.voltairenet.org/ article176927.html [último acceso a 30 de marzo de 2018].

KAYAYAN ALVARADO, Alexi Vicken, La migración árabe a la ciudad de Guatemala de 1950 hasta hoy en día, Tesis de Licenciatura, Guatemala, Universidad del Valle de Guatemala, 2016.

KAYAYAN ALVARADO, Alexi Vicken, "No es delito pensar diferente" [en línea] disponible en https://pensardiferentenoesdelito.wordpress.com/2014/06/03/interpretacion-sociologica-delamigracion-arabe-en-guatemala/ [último acceso a 30 de marzo de 2018].

"La reivindicación palestina en Guatemala", 5 de agosto de 2018. https:// www.plazapublica.com.gt/content/la-reivindicacion-de-palestina-enguatemala [último acceso a 5 de agosto de 2018].

“Memorándum al Presidente Gral. Lázaro Chacón", El Imparcial (3 de Diciembre de 1927), p. 9. MINISTERIO DE FOMENTO, Leyes Protectoras de varios cultivos, Guatemala, Tipografía Nacional, 1882.

POITEVIN DARDÓN, René, El proceso de industrialización en Guatemala, San José, Educa, 1977.

RENGIFO REINA, J., Geografía Económica, Física y Política de Centroamérica, Guatemala, Hispania, 1949.

Rodolfo Abularach conversa con Marivi Véliz, Ciudad de Guatemala, El Librovisor, 2008.

ROSEMBERG FUENTES, V., El Islam Centroamericano / The Central American

Islam. Araucaria, 18.35 (2016), pp. 55-83. 
VILLALOBOS VIATO, Roberto, “Una religión de paz”, Revista D [Diario Prensa Libre] (Noviembre 2016), pp. 17- 18.

\section{NOTAS}

1. En el transcurso de este trabajo, al escribir nombres de personas y lugares, así como apellidos árabes se respetará la grafía de la documentación consultada. Se trata de uno de los primeros aportes elaborados en Guatemala para estudiar la migración palestina, por tanto, existieron pocos referentes para construir la metodología, objetos de estudio y la tesitura narrativa a utilizarse. Por lo valioso que resultaron los aportes de algunas personas a quienes acudí, expreso un agradecimiento al señor Jorge Abed, capacitador de radiotelecomunicaciones de los Bomberos Municipales, miembro de la Asociación Árabe de Guatemala, de ascendencia palestina, quien me facilitó un material básico para estudiar la migración palestina de 1927 en marzo de este año y al mercadólogo Yaman Jomaa al Azanki, nacido en Bekaa, sur de Líbano y con diez años como residente, con quien intercambié algunas impresiones acerca de movimientos migratorios del Medio Oriente entre agosto y octubre. Asimismo, agradezco la prestancia y atención de Ricardo Aguilar Bol, quien me facilitó la consulta del periódico "El Imparcial", cuyos tomos se consultan en la hemeroteca Nacional “Clemente Marroquín Rojas” de ciudad de Guatemala.

2. La temporalidad escogida para definir el régimen político y económico que privaba a la venida de los primeros grupos de inmigrantes palestinos es la del triunfo de la Reforma Liberal en Guatemala y la de finalización de la dictadura de Tiburcio Carías Andino, el último dictador de este signo político en la región.

3. Pascal Herren, "Voltairenet.com. 12 de Diciembre de 2012", http://www.voltairenet.org/ article176927.html, último acceso a 30 de marzo de 2018.

4. Guatemala, El Salvador, Honduras, Nicaragua y Costa Rica, territorios que también formaron la Capitanía General del Reyno de Goathemala durante la colonia, un período que cronológicamente se puede ubicar entre 1524 y 1821.

5. Rosemberg Fuentes, Velvet, 2016, "El Islam centroamericano".

6. Equívoco sumamente frecuente entre funcionarios de gobierno, escritores y periodistas, que definieron a los palestinos y a los demás inmigrantes árabes que arribaron antes de 1917 a partir de identificarlos con el pasaporte que portaron.

7. Al tratarse de grupos con marcada tendencia a la formación de redes familiares, la prosopografía es uno de los métodos que revelan más información y detalles acerca de la forma de reproducción del capital, sus alianzas y la inserción en círculos elitarios conformados por otras pertenencias étnicas como finalmente sucedió en los países de arribo, donde el capital y los recursos obtenidos por los palestinos, les llevó a conformar alianzas con grupos oligárquicos tradicionales. Un ejemplo de ello es la familia Abularach, de gran presencia en Guatemala, cuyos primeros miembros, según el pintor Rodolfo Abularach, los hermanos Natalio y Jorge arribaron hacia 1893. Documentación de archivo da cuenta que, anteriormente a ellos, Antonio Abularach se desempeñaba como comerciante. Luego, varios miembros del clan Abularagge, árabes cristianos provenientes de Bethlehem, (Belén), donde se desempeñaron como traductores para los peregrinos europeos que arribaban para visitar la Capilla de la Natividad. En el inciso numerado 2.3 del presente trabajo existe un abordaje más extenso a este respecto.

8. Varía el número de asesinados en la misma. Las cifras oscilan entre 100 y 250. Ciertamente, las fuentes se encuentran plenamente politizadas, como parte del conflicto, lo que brinda gran variabilidad a las cifras que se difunden en enciclopedias y artículos de investigación. Es importante conocer estos hechos de violencia, pues los mismos muestran los niveles de la animadversión y animosidad entre ambos grupos. No obstante ser la migración un problema 
multicausal, es necesario sopesar el papel de los desplazamientos territoriales como factor generador de la migración hacia el exterior.

9. René Poitevin Dardón, El proceso de industrialización en Guatemala, San José, Educa, 1977.

10. Estos autores han estudiado la génesis del capitalismo guatemalteco desde distintas posiciones teóricas, coincidiendo en el carácter periférico del proceso de construcción de las relaciones de producción e infraestructura jurídico-política necesarias para monetizar la economía y canalizar la fuerza de trabajo de indígenas y mestizos.

11. Los grupos liberales locales hicieron uso, en algunos momentos, de la palabra "industria" para nombrar al comercio o la manufactura, lo que nunca denominó a la producción fabril propiamente dicha por la carencia de tecnología para activar fábricas. En su vocabulario, los intelectuales asumieron eso como una condición necesaria para la modernización de la sociedad, lo cual, por las particularidades del desarrollo económico no coincidía con la realidad. Esta "industria", jamás llevó a la producción de mercancías a realizarse en el mercado, por cuanto no se trataba de productos industriales sino de frutos de la tierra (añil, grana, café, azúcar) mismas que si bien eran intercambiadas con valor agregado, no procedían de un proceso industrial. El esquema clásico no era el de M-D-M explicado por Marx. Por ello, en el vocabulario oficial, las personas que recibían concesiones del gobierno para establecer plantaciones en tierras con potencialidades productivas eran denominados "empresarios", sin que esto significara la existencia de un marco legal para la actividad empresarial, contratación de fuerza de trabajo o régimen salarial. Ejemplo de ello es la legislación de Fomento a diversos cultivos sancionada por Justo Rufino Barrios en las "Leyes Protectoras de varios cultivos", editada en junio de 1882. Ministerio de Fomento, "Leyes Protectoras de varios cultivos", Guatemala, Tipografía Nacional, 1882.

12. Entre ellos están dos trabajos que prestaron gran utilidad al autor, la tesis "El papel de los inmigrantes palestinos en Honduras 1900-1950", del hondureño Jorge Alberto Amaya Vanegas, impresa en Tegucigalpa en 1995 y "El Islam centroamericano" de Rosemberg Fuentes, Velvet, 2016. Hasta el momento, ningún guatemalteco nativo y sin vinculación con grupos árabes ha dedicado tiempo y esfuerzo al estudio los palestinos. Asimismo, no se sabe de un trabajo colectivo que aborde a este grupo. Quien sí lo ha hecho es Alexi Vicken Kayayan Alvarado, por línea paterna, descendiente de libaneses de etnia armenia y lo ha hecho con "La migración árabe a la ciudad de Guatemala de 1950 hasta hoy en día", Tesis de Licenciatura, Guatemala, Universidad del Valle de Guatemala, 2016.

13. A la fecha, en ambos países se ha elegido a varios presidentes de la República, existiendo también líderes políticos, comerciales y financieros pertenecientes a la misma. En Guatemala, el único caso de un mandatario de ascendencia árabe es el del expresidente Jorge Antonio Serrano Elías (1990-1993), alejado del cargo tras un autogolpe de Estado. con ascendencia libanesa por la línea materna.

14. Para el caso de los palestinos en Guatemala, resulta insoslayable abordar a la familia Abularach, lo que se realizará más adelante en este artículo. Se trata de un grupo que no se limita a este país, sino que cuenta con proyecciones hacia otros, como México, El Salvador, Honduras y Bolivia. Un factor que incidió en su aceptación y rápida integración ha sido la religión, que siendo cristiana ortodoxa, no planteó mayores problemas en naciones de mayoría católica.

15. A la fecha, no existe un incentivo institucional al respecto, permaneciendo estas temáticas "vírgenes", sin tocar por así decirlo. Además de ello, hay que señalar que el grupo palestino ha constituido una comunidad fuertemente unida por el vínculo cultural e idiomático, con poca proyección fuera de sí, lo que dificulta el abordaje de su origen, inserción y evolución como grupo por cientistas. Algunas familias, como la Abularach, son, parte de una élite comercial que controla algunos rubros (aceros, textiles, tabacos) y sostiene un bajo perfil, sin involucrarse fuertemente en la política hasta el siglo XXI. Otro elemento que también debe tomarse en cuenta cuando se explica la carencia de estudios que traten sobre los árabes en Guatemala es que, dada la 
vocación comercial del grupo, su orientación en cuanto a carreras universitarias les lleva a elegir carreras técnicas y con relación a las Ciencias Económicas, lo que incide en el escaso interés en esclarecer sus orígenes y la forma en que se insertaron en la sociedad. Al respecto de este problema, es bueno decir que, las dificultades en encontradas en el acopio de datos de los palestinos y las colonias extranjeras se dificulta en las fuentes gubernamentales porque ellos no poseen visibilización en los Censos Nacionales de Población llevados a cabo periódicamente, por ejemplo, en los realizados en 1981 y 2002 no existe una posibilidad de contabilizar cuántos encuestados se adscribieron a la pertenencia étnica o cultural árabe, puesto que, las únicas opciones de identificación presentadas fueron "indígena" o "no indígena". Igualmente se procedió en Censo Nacional de Población y Vivienda realizado en el segundo semestre del presente año 2018. Anteriormente, las boletas de inscripción de nacimiento tenían 4 opciones para registrar la pertenencia étnica de los recién nacidos: a) Indígena, b) Ladina-mestiza, c) Negra y d) Amarilla. También, el DPI, Documento Personal de Identidad, documento único para identificarse y realizar trámites bancarios y migratorios que sustituyó a la Cédula de Vecindad desde inicios de la segunda década del siglo XXI, solamente tiene como opciones para expresar pertenencia étnica las opciones: maya, ladino-mestizo, garífuna y xinca. Como puede evidenciarse, la visibilización de los árabes palestinos corre por cuenta de investigadores que protagonicen esfuerzos independientes.

16. La sangrienta ocupación territorial y la represión del movimiento de liberación nacional constituyen también condicionantes para abandonar Palestina según Vicken Kayayan, esto ha diversificado la migración hacia Guatemala y ya no se da solamente desde Belén y Taybeh, sino que se extiende a Ramalah, Nablus y Jerusalén, invocada por Israel como su capital histótica. Ver artículo: "La reivindicación palestina en Guatemala", https://www.plazapublica.com.gt/content/lareivindicacion-de-palestina-en-guatemala, 5 de agosto de 2018.

17. Un rastreo a la grafía original del apellido lleva a "Abu al Araj" (transliteración أبولاراش) o "Los Traductores", uno de las familias del clan Tarahmej, descendientes de la mezcla entre árabes y misioneros italianos trasladados a Tierra Santa en el siglo XVIII. Una de las subdivisiones de la familia Tarahmej, de la cual descienden es Giacamán o Yacamán, con presencia en Centroamérica, de lo que se puede deducir una filiación italiana. Vivían en la "Calle de la Estrella" y guiaban a los peregrinos que visitaban la Iglesia de la Natividad. Existe una rama de esta familia en México, la Abularach Talamás, asentada en Torreón Coahuila hacia 1913, también originaria de Belén. Corona Páez Sergio Antonio, "Los Abularach Talamás", en "Firmas: crónica de Torreón" 28 de junio de 2015, enlace web: http://www.milenio.com/firmas/dr-_sergio_antonio_corona_paez/ Abularach-Talamas_18_543725657.html En Guatemala arribó hacia 1893. De ellos desciende José Luis Gabriel Abularach, jerarca y fundador de "Aceros de Guatemala", heredero de la cadena de almacenes "El Tirador", así como Minas de Guatemala S.A.

18. Material facilitado por el señor Jorge Abed, hermano de quien redactó dichos apuntes, capacitador de radiotelecomunicaciones de los Bomberos Municipales de ciudad de Guatemala en el presente (2018). El mismo contiene, entre otros aspectos sumamente valiosos, algunas fotografías de los grupos de palestinos que arribaron al país, en las que se pueden apreciar los vínculos familiares de hombres y mujeres de destacada participación en círculos comerciales. " $\mathrm{L} a$ comunidad palestina en Guatemala", Dr. Freddy Abed, documento inédito, Ciudad de Guatemala, julio de 1999, págs. 1-4.

19. Archivo General de Centroamérica (AGCCA), box 7837, exp. 18372, leg. 765, folios 1-3.

20. AGCA, bx. 78.7, exp. 13675, leg. 653, folios 1-2.

21. AGCA, B. 78.7, exp. 13675, leg. 653, folios 1-2.

22. AGCA, B.78.32, exp. 35829, leg. 1495, folio 1.

23. El sorteo tendría lugar otorgando papeles "en blanco" y otros con el nombre de algún bien o artículo como premio a los clientes, lo que se haría en presencia de un representante de las autoridades, lo que es denegado como sucedió con varias peticiones de comerciantes según lo 
muestra la documentación existente en el Archivo General de Centroamérica. AGCA, bx. 78.32, exp. 35829, leg. 1495, folios 1-3.

24. Referencias que proporcionó Rodolfo Abularach (n. 1937) en la entrevista que le realizó la periodista y artista Marivi Véliz. Entre los datos que destacan de esta interacción es el hecho de que el entrevistado refiere el hecho de que es hijo de primos palestinos y que la familia - afincada en Guatemala después que le agradó el país, decidiendo ya no dirigirse a Colombia, como era su cometido-, una vez afiliada al catolicismo después de ser maronitas, pidió autorización al Vaticano para llevar a cabo el matrimonio. Ver: "Rodolfo Abularach conversa con Marivi Véliz", El Librovisor, Publicaciones Alternativas del Centro Cultural de España en Guatemala, Colección Pensamiento volumen II, tomo I, pags. 6-7.

25. La cadena de almacenes existe en la actualidad. De la misma surgió el capital para iniciar el desarrollo del emporio "Aceros de Guatemala", cuya cabeza es José Félix Vicente Gabriel Abularach desde mediados del siglo XX. Empezó a despuntar desde la compra de la fábrica de clavos INFENA, propiedad de Enrique Arzú. En ese momento, la comercialización de productos de hierro y acero lo realizaba un conjunto de importadores de origen alemán (León Guttmann, Freddy y Milton Köenigsberg entre otros). Gabriel Abularach logró un acuerdo con ellos hasta lograr imponerse, lo cual le facilitó el camino a convertir su empresa en monopolio y el ascenso a la élite industrial, con lo que consolidó su poder. Ver: https://www.plazapublica.com.gt/content/acerosde-guatemala-un-emporio-creado-con-privilegios-del-estado-13

26. Bill Barreto, "Aceros de Guatemala, un emporio creado con la ayuda del Estado", parte I, Guatemala, 29 de Junio de 2017. Este analista replica el juicio realizado por estudiantes e interesados en este movimiento migratorio. Los inmigrantes palestinos y demás árabes dedicados al comercio constituyeron un grupo emergente que ocupó un espacio hegemonizado por españoles pobres, italianos y alemanes, por lo que fue recibido con recelo debido a su procedencia, cultura e idioma.

27. AGCA, bx. 78.22, exp. 15585, leg. 705 folios 1-3. En este reservorio no existe documentación sobre la familia Dacaret, también de origen palestino y también dedicada preferentemente al comercio como la Abularach.

28. Material disponible al público en la página de redes sociales "Genealogía Abularach", fuente: página "Genealogía Abularach" https://www.facebook.com/GenealogiaAbularach-153344181419235/ gestionado por algunos descendientes de la familia residentes en Guatemala.

29. Los documentos consultados también dan fe del casamiento de su hermano Giubrail, casado en agosto de 1684 con María Mussa, nacida en Belén en 1662. El documento no refiere la fecha de nacimiento del contrayente masculino.

30. En este país, representaron un grupo que se abrió paso a la emergencia sin confrontar a los grupos dirigentes, pues se abstuvo de la política y la participación en la constitución de los cuadros políticos y fracciones del régimen liberal. A pesar de que, como está dicho, tenían ya presencia antes del inicio del siglo XX, continuaron arribando con la migración de 1927. Paulatinamente, han conquistado un lugar en la sociedad, contando, en el presente con una insignia en la heráldica con la que algunos linajes criollos reivindican su origen nobiliario.

31. Todos estos detalles han sido obtenidos analizando los documentos escaneados que se encuentran a la vista pública en la página "Genealogía Abularach". Constituyen un reservorio valioso de referencias sobre este grupo dada la carencia de bibliografía especializada en estos temas en Guatemala, lo que puede aprovecharse para un trabajo focalizado en la familia.

32. Algunas personalidades destacadas de esta familia con proyección al exterior del ambiente comercial e industrial son el artista plástico Rodolfo Abularach (1933), el político, empresario y excanciller guatemalteco en el período 2004-2008 Jorge Briz Abularach (1955) y el arquitecto Eduardo Andrade Abularach (1964). 
33. Hoja de control escaneada y colocada a la consulta pública en la página "Genealogía Abularach" fuente: página "Genealogía Abularach" (https://www.facebook.com/GenealogiaAbularach-153344181419235/)

34. Freddy Abed, La comunidad palestina en Guatemala, Guatemala, Asociación Árabe de Guatemala, 1999.

35. El arribo del barco pasó desaparecido para los medios de comunicación gubernamentales y privados. Al igual que sucedía con los migrantes chinos, muchos de los provenientes del Medio Oriente "entraban" de forma clandestina, sobornando a las autoridades aduaneras portuarias y de puestos fronterizos. En el mes de noviembre de 1927, cuando arribó el "Rugía" los redactores del Diario "El Imparcial" se preocupaban más del naufragio del "Mafalda", un trasatlántico italiano siniestrado frente a Salvador de Bahía, Brasil, que de los buques y barcos que atracaban en Puerto Barrios, Izabal. Diario “El Imparcial”, 10 de noviembre de 1927, p. 1.

36. Asoma ya, en los nombres propios, una filiación cristiana, puesto que, proviniendo de una región de lengua y cultura árabe y religión mayormente musulmana, se encuentran nombres como Tomás y Mijail, nombre este último que podría transformarse fácilmente en el latino Miguel. F. Abed, La comunidad palestina ..., pp. 1-4.

37. Se presentan variaciones del apellido en países vecinos, con lo que el mismo se escribe Kuri o Khouri, tal como se observa en algunos casos de políticos y empresarios de origen libanés en México, Perú y otros países.

38. Tradicionalmente, los departamentos de Escuintla, Santa Rosa, Retalhuléu y Suchitepéquez, en los que se desarrolla la producción ganadera en grandes haciendas que surten los mercados capitalinos.

39. La narrativa de Freddy Abed muestra una confluencia entre los argumentos de René Poitevin y Jorge Alberto Amaya Vanegas. Estos métodos de comercialización fueron claves en la acumulación realizada por los primeros migrantes palestinos tanto en Honduras como en Guatemala.

40. En el caso de los alemanes, Guatemala se distingue entre otros países. Cualquier revisión a periódicos como "El Imparcial" (fundado en 1922) y "El Diario de Centroamérica" (oficial, comenzó a circular en 1875 bajo el nombre de "El guatemalteco") anterior a 1945 es abundante en publicidad para las casas comerciales alemanas, así como para servicios ofrecidos por ciudadanos germanos, algo difícil de encontrar en países vecinos.

41. F. Abed, La comunidad palestina ....

42. Argumento sostenido por la historiadora Regina Wagner Henn en la conferencia "Guatemala y la Primera Guerra Mundial 1914-1918”, Academia de Geografía e Historia de Guatemala, 21 de noviembre de 2018. Este argumento tiene un gran peso para justificar las restricciones a la migración árabe en Guatemala, debido a que, en ese entonces, los intereses otomanos compatibilizaron con los del Imperio Alemán y Estados Unidos presionó para limitar la movilidad de los súbditos de alemanes y ciudadanos provenientes del Imperio Turco, así como practicar medidas expropiatorias, lo que afectó a las propiedades alemanas.

43. El Imparcial, "Memorándum al Presidente Gral. Lázaro Chacón", 3 de Diciembre de 1927, p. 9.

44. Idem.

45. Los redactores del documento no consignan desde donde se dio el aumento. Y cuál es el porcentaje de este.

46. Idem.

47. Idem.

48. Idem.

49. El Imparcial, "En defensa de los tabacos del Oriente", 17 de Diciembre de 1927, pp. 1-4.

50. La necesidad de regulación de este renglón productivo hizo que, hacia 1934, se estableciera una Ley para regular la siembra, producción y comercialización del tabaco por el gobierno de Jorge Ubico Castañeda (1931-1944). Antes de la existencia de las transnacionales tabacaleras, 
algunas fábricas locales tuvieron necesidad de acogerse al proteccionismo estatal ante el contrabando ejercido desde México por algunos grupos de comerciantes que medraban revendiendo el producto.

51. Jorge Alberto Amaya Banegas, El papel de los inmigrantes palestinos en Honduras 1900-1950, Tegucigalpa, 1995. Según Wael Radi, hijo del comerciante Mustafá Radi, de Ramallah, cuando su padre arribó a Guatemala, hacia 1971, no había en el país más de cuatro o cinco musulmanes. Para la fecha, todos los palestinos se concentraban en la ciudad de Guatemala, lo que ha cambiado en décadas posteriores. La cifra de adeptos al Islam proporcionada sugiere pensar en la predominancia de las familias provenientes de clanes cristianos como el Abularach en la migración. Gemma Gil Flores, "Musulmanes en Guatemala", Revista D, Diario "Prensa Libre", 5 de junio, 2005, pp. 20-21.

52. Guatemala registró, en la última década del siglo una gran afluencia de jordanos. En algunos momentos, quienes se trasladaron eran varones solteros dedicados al comercio según los edictos de nacionalización que fueron frecuentes en periódicos como "el Gráfico" (Extinto hacia 1998), "Diario de Centroamérica" (oficial, vigente) y "La Hora" (vigente, cercano al siglo de circulación), los únicos que circulaban en la ciudad capital vendiendo espacio para la publicación de resoluciones legales. Ellos, siguiendo la lógica de otros migrantes árabes, especialmente palestinos y libaneses, se insertaron en las ramas del comercio de textiles, electrodomésticos y otros productos.

53. Guatemala ha perdido, actualmente, la mayoría católica de aquellos tiempos. Debido al arribo de las iglesias neopentecostales y otras denominaciones, así como a su agresiva expansión, los resultados de los censos religiosos denotan paridad con los movimientos protestantes, algo insólito en los países de la región. El país es centro de misiones evangélicas a otras naciones y también un aliado firme a Israel, tal como lo prueba la reciente decisión del presidente Jimmy Morales, de confesión protestante, de respaldar la iniciativa estadounidense de reconocer a Jerusalén como la capital del Estado hebreo en perjuicio de la causa palestina.

54. Las mezquitas existentes, en las que desarrollan sus actividades los pobladores musulmanes, son de reciente fundación, siendo la primera, Baitul Awal ubicada en el municipio de Mixco, sobre la carretera Interamericana construida por un grupo heterodoxo, la Misión Ahmaddiya, con raíces en Pakistán en la obra y enseñanza del místico Hazrat Mirza Ghulam Ahmad (1835-1908), nacido en Qadian, hoy India. La fundación de dicha congregación ha permitido el desarrollo de proyectos sociales como la fundación de una clínica médica funcionando de forma anexa al templo en 1991 (dos años después de construida la mezquita) y, recientemente, el inicio de la construcción del Hospital Nasir, edificado en honor a Nazir Muhammad, sucesor de Mirza Ghulam en territorio del Municipio de Santa María Cauqué, departamento de Sacatepéquez. Óscar Felipe Q., artículo "Hospital Nazir hará labor social con los más pobres de Guatemala”, Diario Prensa Libre, julio 3 de 2017, enlace web: http://www.prensalibre.com/ciudades/guatemala/ hospital-nasir-hara-labor-social-con-los-mas-pobres-de-guatemala. Asimismo, en Guatemala ha hecho presencia el islam sunní (ortodoxo), nucleado en la mezquita Al Da'wa, situada en la ciudad capital y dirigida por el imán egipcio Fahed Himeda el-Sagini desde 2015. Entre los miembros de la comunidad palestina, al menos en el documento facilitado por el sr. Jorge Abed, se encuentra que la gran mayoría de quienes arribaron a Guatemala en 1927 eran cristianos de rito oriental, por lo cual sería un grave error coludir a los musulmanes con los árabes y palestinos.

55. La familia Abularach es, con mucho, una de las más importantes de esta comunidad. En Guatemala se han colocado en el mismo nivel que los sectores tradicionales que tenían acceso a la riqueza como parte de un prestigio obtenido por derecho de sangre. La mayor parte de los criollos españoles conservaron la pureza de su origen hasta entrado el siglo XIX, cuando se revitalizaron con la "entrada" de algunos europeos occidentales a las redes familiares locales, existiendo también una red oligárquica formada casi completamente por alemanes, propietarios de grandes latifundios en que se realizaba la producción cafetalera. 
56. Según Jamal Mubarak, presidente en 2005 de la comunidad Islámica de Guatemala, en el país podían encontrarse residiendo aproximadamente 100 familias musulmanas, el $95 \%$ de ellas de origen palestino y el resto, libaneses, sirios, egipcios y jordanos. No se puede hablar de que se trate de residentes permanentes, sobretodo en el caso de los comerciantes varones, que viajan frecuentemente. G. Gil Flores, "Musulmanes en Guatemala". Más recientemente, para el religioso egipcio Fahed Himeda el-Sagini, imán de la mezquita al Da’wa, el número de musulmanes es estimado en 350, la mayor parte palestinos. Roberto Villalobos Viato, "Una religión de paz", Revista D. Diario Prensa Libre (Noviembre 2016), pp. 17-18.

57. F. Abed, La comunidad palestina....

58. Los gobiernos liberales tuvieron entre sus prioridades el control social de la población. El año de 1932, segundo en el poder del autócrata Jorge Ubico Castañeda, fue de un aumento de la vigilancia sobre las expresiones organizadas debido a la rebelión indígena y campesina desarrollada en el vecino El Salvador, que tanto marcaría las políticas de control social de los años venideros.

59. Esta ley es invocada como una medida xenófoba y racista que impidió la continuidad de la migración palestina. Vinken Kanyayan, "Interpretación sociológica de la inmigración árabe a Guatemala", en artículo "No es delito pensar diferente", ensayo elaborado para el curso de Sociología de América Latina impartido en la Universidad Del Valle de Guatemala 24 de mayo de 2014, enlace web, https://pensardiferentenoesdelito.wordpress.com/2014/06/03/interpretacionsociologica-de-la-migracion-arabe-en-guatemala/

60. Esta prohibición refleja un tinte racista y una actitud de exclusión en las autoridades, lo que se explica por el desvelo de los liberales por atraer la migración de agricultores y artesanos de Europa Occidental para introducir nuevas actividades productivas y elevar el nivel de vida en el país con anterioridad.

61. J. Rengifo Reina, Geografía Económica, Física y Política de Centroamérica, Guatemala, Hispania, 1949.

62. Esta circunstancia se infiere de los nombres de muchos empresarios consignados en anuncios de comercios y empresas existentes en el país a inicios del siglo XX. En el diario "El Imparcial", uno de los medios escritos de mayor tiraje y alcance en el país, se encuentran páginas enteras de anuncios de productos y servicios proporcionados por empresas y negocios regidos por alemanes, muchos de ellos con propietarios de nombres hebreos: Abraham, Jacob, etc. Asimismo, sería importante para otro estudio, incorporar a un trabajo que verse sobre estas temáticas las muestras de presencia judeoalemana que evidencian las tumbas construidas en los panteones israelitas de en el Cementerio General y "La Verbena".

63. Los palestinos en ambos países tienen un rol descollante en la economía y política. Para el caso de Guatemala, hace falta una mayor y más amplia profundización y problematización para explicar el recorrido particular que les llevó a constituir una fracción de la clase dominante financiera e industrial en la actualidad.

\section{RESÚMENES}

Este artículo aborda el arribo a Guatemala de la segunda oleada de migrantes palestinos en 1927. La misma es continuación de los desplazamientos iniciados en el siglo XIX, que trasladó a algunas familias de origen palestino a varios países centroamericanos. Aquí se aborda el contexto histórico en el que se insertaron y la forma en que interactuaron con la sociedad guatemalteca. 
Se han resaltado sus actividades económicas y las dificultades que planteaba la existencia de legislación que limitó la migración así como la integración de los residentes y recién llegados a la élite comercial.

Neste artigo abordar-se-á a chegada a Guatemala da segunda vaga de migrantes palestinianos em 1927, na continuidade das deslocações iniciadas no século XIX, que trasladaram algumas famílias de origem palestiniana a vários países centro-americanos. Aqui se aborda o contexto histórico em que estas se inseriram e a forma como interatuaram com a sociedade guatemalteca. Realçam-se as suas atividades económicas e as dificuldades advindas de legislação que limitava a migração bem como a integração dos residentes e recém-chegados à elite comercial.

ÍNDICE

Palabras claves: árabes, generación de 1927, migración, palestinos, Régimen Liberal

Palavras-chave: árabes, geração de 1927, migração, palestinos, regime liberal

\author{
AUTOR \\ NÉSTOR VÉLIZ CATALÁN \\ Universidad de San Carlos de Guatemala \\ nestorvelizct111[at]gmail.com
}

